\title{
Indicators of Overweight and Cardiovascular Disease Risk Factors among 11- to 17-Year-Old Boys and Girls in Germany
}

\author{
Christina Kleiser $^{a, b} \quad$ Anja Schienkiewitz ${ }^{b}$ Angelika Schaffrath Rosario $^{b}$ \\ Reinhild Prinz-Langenohl ${ }^{\mathrm{c}} \quad$ Christa Scheidt-Nave $^{\mathrm{b}} \quad$ Gert B.M. Mensink $^{\mathrm{b}}$ \\ ${ }^{a}$ Institute of Epidemiology I, German Research Center for Environmental Health (GmbH), Helmholtz Zentrum München, Neuherberg, \\ ${ }^{\mathrm{b}}$ Department of Epidemiology and Health Reporting, Robert Koch Institute, Berlin, \\ ${ }^{\mathrm{c}}$ Department of Nutrition and Food Science, University of Bonn, Germany
}

\section{Keywords}

Overweight - Adolescent · Epidemiology ·

Blood pressure $\cdot$ Cholesterol · C-reactive protein · KiGGS

\section{Summary}

Objective: We analyzed the magnitude of the association between cardiovascular disease (CVD) risk factors and various measures of overweight among adolescents, to determine which indicator of overweight is most relevant for risk assessment. Methods: 5,546 boys and girls aged 11-17 years participating in the German Health Interview and Examination Survey for Children and Adolescents (KiGGS) were studied. Overweight was assumed when different anthropometric variables exceeded age- and sex-specific 90th percentiles. Blood pressure was measured and blood samples were analyzed for serum total cholesterol, lipoproteins, high-sensitivity C-reactive protein, and glycosylated hemoglobin (HbA1c). Results: In both sexes, overweight was significantly associated with adverse levels of CVD risk factors, except HbA1c. These associations were most pronounced for overweight as defined by waist circumference (WC), waist-to-height ratio $(\mathrm{WHtR})$, or BMI. Between $11 \%$ and $37 \%$ of the overweight children exceeded the defined cut-offs for individual CVD risk factors, with age- and puberty-adjusted significant odds ratios (95\% confidence interval $(\mathrm{Cl}))$ in comparison to normal-weight age mates ranging from $1.7(1.0-3.0)$ to 6.1 (4.5-8.2). Conclusions: The findings of this population-based survey suggest that, among adolescents, WC, WHtR, and BMI are easily applicable measures of overweight that appear to be relevant for CVD risk assessment.

\section{Introduction}

Clinical and epidemiological studies among children and adolescents have consistently shown that overweight and obesity are associated with major biological cardiovascular disease (CVD) risk factors, such as insulin resistance, high blood pressure, and dyslipidemia [1-9]. In a US national sample of nondiabetic children examined in the third National Health and Nutrition Examination Survey (NHANES III), the BMI was positively related to glycosylated hemoglobin (HbA1c) [10]. Several analyses from the NHANES III also demonstrate that moderately elevated concentrations of C-reactive protein (CRP) correlate with obesity and the metabolic syndrome among children and adolescents [11-13]. Overweight in childhood has also been associated with vascular changes [14], higher blood pressure and poorer lipid risk profile [15], and cardiovascular mortality [16] in later life.

Nevertheless, the relationship between childhood obesity and cardiovascular risk leaves many questions unanswered. Among adults, BMI and measures of central adiposity appear to be predictive of adverse health outcomes [17]. However, there is an ongoing debate whether childhood obesity as defined by BMI is an independent predictor of adult CVD risk, or whether the association is largely confounded by the tracking of BMI from childhood to adulthood [14, 18]. During growth and development, BMI may be a less appropriate measure of obesity than indices more closely related to body fat mass, such as skinfold thickness (SFT) and waist-to-height ratio (WHtR). Only recently, several studies have addressed this question, with large variations in sample size, study variables and methods $[1,3,4,6,8]$. Using the nationally representative German Health Interview and Examination Survey

\begin{tabular}{ll}
\hline KARGER & ( ) 2011 S. Karger GmbH, Freiburg \\
1662-4025/11/0045-0379\$38.00/0 \\
$\begin{array}{l}\text { Fax +49 7614520714 } \\
\text { Information@Karger.de } \\
\text { www.karger.com }\end{array}$ & $\begin{array}{l}\text { Accessible online at: } \\
\text { www.karger.com/ofa }\end{array}$
\end{tabular}

Dr. Gert B.M. Mensink 
for Children and Adolescents (KiGGS), we systematically compared the relationship between CVD risk factors and various indicators of overweight. We asked: (1) Is there a consistent association between overweight measures and various CVD risk factors? (2) Which measure of overweight shows the strongest association with CVD risk factors and may therefore be preferably used for risk assessment and prevention?

\section{Participants and Methods}

\section{Study Population}

The KiGGS study was conducted from May 2003 to May 2006. Design and sampling methods are described in detail elsewhere [19]. In brief, a two-stage clustered and stratified sampling procedure was applied. 167 sample points representative for German communities were selected in proportion to community size and federal state. Within these points, ageand sex-stratified random samples were drawn from local population registries. The response rate was $69 \%$ for 11 - to 13 -year-olds and $63 \%$ for 14- to 17-year-olds. The survey was approved by the Federal Office for Data Protection and by the Charité University Medicine (Berlin) ethics committee. Written informed consent was obtained from all parents or caregivers as well as from participants themselves, if they were 14 years of age or older.

For the present analysis, we excluded participants with chronic health problems or on current medication likely to affect one or more of the CVD risk factors under study. These included participants with a history of type 1 diabetes mellitus $(n=12)$ or hypertension $(n=21)$, participants on lipid-lowering drugs $(n=8)$, antidiabetic medication $(n=8)$, glucocorticosteroids $(\mathrm{n}=8)$ or antihypertensives $(\mathrm{n}=17)$, and girls using oral contraceptives $(n=428)$. We further excluded participants with serum CRP concentrations of $10 \mathrm{mg} / \mathrm{l}$ and higher $(\mathrm{n}=109)$ as this is likely to reflect acute inflammatory processes, and participants for whom anthropometric $(\mathrm{n}=152)$ or laboratory variables $(\mathrm{n}=503)$ were incomplete. Overall, out of 6,813 11- to 17-year-old KiGGS participants, 1,193 (461 boys, 806 girls) were excluded. Thus, our analyses are based on data of the net study sample of 5,546 11- to 17-year-olds, 3,031 boys and 2,515 girls.

\section{Data Collection}

Participants underwent a computer-assisted medical interview and a physical examination conducted by trained medical staff in four study teams. Non-fasting blood samples were collected. Measurements of body height, body weight, triceps and subscapular SFT, waist circumference (WC) and hip circumference (HC) were obtained according to a highly standardized protocol. Body height was measured to the nearest $0.1 \mathrm{~cm}$, using a portable Harpenden stadiometer (Holtain Ltd., Crymych, UK). Body weight was measured to the nearest $0.1 \mathrm{~kg}$ with a calibrated electronic scale (SECA, Birmingham, UK). WC was measured with a flexible non-elastic tape at the smallest abdominal position between the lower rib margin and the iliac crest. $\mathrm{HC}$ measurements were taken at the point yielding the maximum circumference over the buttocks. A Harpenden caliper was used to measure one set of triceps and subscapular SFTs on the right body side with an accuracy of $0.2 \mathrm{~mm}$. 2 readings of systolic and diastolic blood pressure (SBP, DBP) were obtained using an automated oscillometric device at an interval of $2 \mathrm{~min}$. The arithmetic mean of the 2 measured values was used for the analysis.

To assess the pubertal stage, participants were asked to categorize their pubic hair status according to Tanner stages 1-6 [20]. Pubertal stage was used as a confounder variable in the analysis and was defined as prepubertal (Tanner stage 1), pubertal (Tanner stage 2 or 3), or post-pubertal (Tanner stages 4-6).

\section{Laboratory Assays}

Serum was separated and analyzed according to a highly standardized protocol [19]. Total cholesterol (TC) was analyzed using an enzymatic assay (cholesterol oxidase-PAP method) (Roche, Mannheim, Germany). Low-density lipoprotein cholesterol (LDL-C) and high-density lipoprotein cholesterol (HDL-C) were measured directly with a homogeneous enzymatic colorimetric assay (Roche). High-sensitivity C-reactive protein (hs-CRP) was measured by an immunoturbidimetric assay. The initially applied assay (Scil Diagnostics, Martinsried, Germany) was withdrawn from the market in 2004 and was replaced by an equivalent assay from a different provider (Roche, Mannheim, Germany). A correction factor calculated with a Passing Bablok regression equation was used for the analysis. Glycosylated hemoglobin (HbA1c) was analyzed using highperformance liquid chromatography (HPLC; Diastat, Bio-Rad, Munich, Germany).

\section{Operationalization of Study Variables}

BMI was computed as the ratio of the body weight in $\mathrm{kg}$ and the squared body height in $\mathrm{m}^{2}$. The ratio of $\mathrm{WC}$ in $\mathrm{cm}$ to $\mathrm{HC}$ in $\mathrm{cm}$ (WHR), the ratio of WC in $\mathrm{cm}$ to body height in $\mathrm{cm}$ (WHtR) and the sum of 2 SFT measurements were also calculated. Overweight was defined when values exceeded the 90th sex- and age-specific percentile (> P90) for each of the anthropometric measures: BMI, WC, WHR, WHtR, and SFT measures (triceps SFT, subscapular SFT, and sum of SFT). These explanatory variables were treated as categorical variables throughout the analyses. In order to allow statistically unbiased comparisons between the various indicators of overweight, the percentiles were based on the net study sample so that an equal number of study subjects were characterized as overweight for each of the indicators. For the CVD risk factors, the 90th ageand sex-specific percentiles of the KiGGS study population were used to define elevated levels of SBP, DBP, and serum concentrations of TC, LDL-C, and HbA1c. The 10th age-and sex-specific percentile of HDL-C was chosen as a cut-off point for low serum HDL-C, and $2.1 \mathrm{mg} / \mathrm{l}$ as the cut-off for serum hs-CRP [12].

\section{Statistical Analyses}

All analyses were stratified by sex and used sampling weights as previously described [19]. The SAS survey procedures (SAS version 9.2) were applied, in order to take the clustered sampling design into account. Descriptive statistics were computed for all continuous study variables. Means and corresponding $95 \%$ confidence intervals (CIs) were calculated stratified by age group and sex. Univariable regression models were conducted to evaluate statistically significant differences between boys and girls and between age groups. Means of selected CVD risk factors according to age group, gender, and indicator of overweight were calculated and displayed graphically. The prevalence of boys and girls with adverse CVD risk factor levels (> P90; except HDL-C: < P10 and hs-CRP: $>2.1 \mathrm{mg} / \mathrm{l}$ ) was assessed according to overweight status (> P90 vs. $\leq$ P90) for the various overweight indicators. Linear regression models were calculated with individual CVD risk factors as dependent variables and the different indicators of overweight as main explanatory variable (> P90 vs. $\leq$ P90). Regression models were adjusted for age in years and pubertal stage as categorical variables. The coefficient of determination ( $\mathrm{R}$ squared) of the regression models was used to estimate the proportion of variability explained by the model. Regarding SBP and DBP, we conducted a sensitivity analysis using age- and height-adjusted z-scores instead of the actual blood pressure readings. As results were unchanged, only the results based on the actual blood pressure readings are presented.

\section{Results}

As presented in table 1, mean body height and weight as well as BMI and WC increased with age group in both sexes 
Table 1. Means (95\% CI) of anthropometric data and cardiovascular risk factors by gender and age group

\begin{tabular}{|c|c|c|c|c|}
\hline & \multicolumn{2}{|l|}{ Boys } & \multicolumn{2}{|l|}{ Girls } \\
\hline & $\begin{array}{l}11-13 \text { years } \\
\mathrm{n}=1,364\end{array}$ & $\begin{array}{l}14-17 \text { years } \\
\mathrm{n}=1,667\end{array}$ & $\begin{array}{l}\text { 11-13 years } \\
\mathrm{n}=1,312\end{array}$ & $\begin{array}{l}14-17 \text { years } \\
\mathrm{n}=1,203\end{array}$ \\
\hline Height, cm & $156.2(155.6-156.8)$ & $175.4(175.0-175.8)$ & $156.7(156.3-157.2)$ & $164.9(164.5-165.4)$ \\
\hline Weight, kg & $48.4(47.6-49.3)$ & $66.9(66.2-67.6)$ & $49.3(48.5-50.1)$ & $59.2(58.4-60.0)$ \\
\hline BMI, $\mathrm{kg} / \mathrm{m}^{2}$ & $19.6(19.4-19.9)$ & $21.7(21.5-21.9)$ & $19.9(19.6-20.1)$ & $21.7(21.5-22.0)$ \\
\hline Subscapular skinfold thickness, mm & $9.9(9.5-10.4)$ & $10.5(10.2-10.8)$ & $11.4(11.0-11.9)$ & $13.4(13.0-13.9)$ \\
\hline Sum of skinfold thickness, mm & $24.7(23.8-25.6)$ & $23.2(22.5-23.8)$ & $28.0(27.2-28.9)$ & $32.9(32.0-33.8)$ \\
\hline Waist circumference, $\mathrm{cm}$ & $68.4(67.7-69.0)$ & $75.0(74.6-75.5)$ & $66.3(65.8-66.9)$ & $69.6(69.1-70.2)$ \\
\hline Waist-to-hip ratio & $0.83(0.83-0.84)$ & $0.81(0.81-0.81)$ & $0.78(0.77-0.78)$ & $0.74(0.74-0.74)$ \\
\hline Waist-to-height ratio & $0.44(0.43-0.44)$ & $0.43(0.43-0.43)$ & $0.42(0.42-0.43)$ & $0.42(0.42-0.43)$ \\
\hline Total cholesterol, mg/dl & $163.3(161.4-165.2)$ & $152.2(150.7-153.8)$ & $163.2(161.4-165.0)$ & $162.2(160.2-164.1)$ \\
\hline LDL-C, mg/dl & $91.3(89.7-92.8)$ & $85.4(84.1-86.8)$ & $92.6(91.0-94.3)$ & $91.8(90.0-93.5)$ \\
\hline HDL-C, mg/dl & $58.2(57.3-59.1)$ & $51.6(50.9-52.3)$ & $57.5(56.7-58.3)$ & $58.2(57.3-59.1)$ \\
\hline Systolic blood pressure, $\mathrm{mm} \mathrm{Hg}$ & $110.0(109.3-110.7)$ & $120.8(120.0-121.6)$ & $110.4(109.7-111.1)$ & $113.5(112.8-114.2)$ \\
\hline Diastolic blood pressure, $\mathrm{mm} \mathrm{Hg}$ & $65.9(65.4-66.4)$ & $70.2(69.7-70.7)$ & $66.0(65.4-66.5)$ & $68.6(68.1-69.1)$ \\
\hline HbA1c, \% & $4.9(4.9-5.0)$ & $4.9(4.9-4.9)$ & $4.9(4.8-4.9)$ & $4.8(4.8-4.9)$ \\
\hline hs-CRP, mg/l & $0.7(0.7-0.8)$ & $0.9(0.8-0.9)$ & $0.7(0.6-0.7)$ & $0.8(0.7-0.8)$ \\
\hline
\end{tabular}

$\mathrm{CI}=$ Confidence interval; hs-CRP = high-sensitivity C-reactive protein.

Table 2. Prevalence ( $\%(95 \%$ CI $)$ ) of children exceeding cut-offs for CVD risk factors according to overweight ${ }^{\mathrm{a}}$

\begin{tabular}{|c|c|c|c|c|c|c|}
\hline & $\mathrm{BMI} \leq \mathrm{P} 90$ & $\mathrm{BMI}>\mathrm{P} 90$ & $\mathrm{WC} \leq \mathrm{P} 90$ & $\mathrm{WC}>\mathrm{P} 90$ & $\mathrm{WHtR} \leq \mathrm{P} 90$ & WHtR > P90 \\
\hline Boys, $\mathrm{n}$ & 2741 & 290 & 2746 & 285 & 2753 & 278 \\
\hline $\mathrm{TC}>\mathrm{P} 90, \mathrm{n}=284$ & $8.0(6.9-9.1)$ & $19.5(14.0-25.1)$ & $8.3(7.1-9.4)$ & $17.3(12.3-22.3)$ & $8.0(6.9-9.1)$ & $19.4(14.1-24.8)$ \\
\hline LDL-C $>$ P90, $\mathrm{n}=305$ & $9.1(7.9-10.2)$ & $19.7(14.4-25.0)$ & $9.3(8.1-10.4)$ & $17.9(13.2-22.6)$ & $9.1(7.9-10.3)$ & $19.7(14.6-24.8)$ \\
\hline HDL-C $<$ P10, $\mathrm{n}=290$ & $7.9(6.7-9.2)$ & $26.4(20.8-32.0)$ & $7.6(6.4-8.9)$ & $29.1(23.3-34.9)$ & $7.9(6.6-9.2)$ & $27.0(21.0-33.1)$ \\
\hline $\mathrm{SBP}>\mathrm{P} 90, \mathrm{n}=359$ & $9.2(7.8-10.6)$ & $34.3(28.4-40.2)$ & $8.9(7.6-10.3)$ & $36.8(30.2-43.4)$ & $9.5(8.1-10.9)$ & $31.7(24.9-38.4)$ \\
\hline $\mathrm{DBP}>\mathrm{P} 90, \mathrm{n}=265$ & $8.1(6.8-9.3)$ & $18.2(13.0-23.4)$ & $7.8(6.5-9.0)$ & $21.0(15.7-26.3)$ & $7.9(6.6-9.1)$ & $20.1(14.6-25.5)$ \\
\hline $\mathrm{HbA} 1 \mathrm{c}>\mathrm{P} 90, \mathrm{n}=282$ & $9.9(7.9-11.9)$ & $10.2^{\text {n.s. }}(6.2-14.2)$ & $10.0(8.0-12.0)$ & $9.7^{\text {n.s. }}(5.6-13.8)$ & $9.9(7.9-11.9)$ & $10.2^{\text {n.s. }}(5.6-14.7)$ \\
\hline hs-CRP > $2.1 \mathrm{mg} / \mathrm{l}, \mathrm{n}=262$ & $7.2(6.0-8.4)$ & $24.3(18.7-29.9)$ & $7.1(5.8-8.3)$ & $25.5(20.1-30.9)$ & $6.9(5.7-8.1)$ & $27.1(21.3-33.0)$ \\
\hline Girls, n & 2265 & 250 & 2275 & 240 & 2271 & 244 \\
\hline $\mathrm{TC}>\mathrm{P} 90, \mathrm{n}=207$ & $7.3(5.9-8.6)$ & $14.4 * *(9.1-19.7)$ & $7.4(6.0-8.8)$ & $13.0 *(7.8-18.1)$ & $7.5(6.1-8.8)$ & $12.5^{\text {n.s. }}(7.4-17.6)$ \\
\hline LDL-C $>$ P90, $\mathrm{n}=180$ & $6.9(5.6-8.1)$ & $12.7 *(8.2-17.2)$ & $7.0(5.7-8.3)$ & $11.2^{\text {n.s. }}(6.9-15.5)$ & $7.1(5.8-8.4)$ & $10.8^{\text {n.s. }}(6.7-14.9)$ \\
\hline HDL-C $<$ P10, $\mathrm{n}=251$ & $7.8(6.4-9.3)$ & $27.9(21.0-34.8)$ & $7.7(6.3-9.1)$ & $29.5(22.3-36.7)$ & $7.7(6.2-9.1)$ & $29.6(22.4-36.8)$ \\
\hline $\mathrm{SBP}>\mathrm{P} 90, \mathrm{n}=264$ & $8.7(7.1-10.3)$ & $28.3 *(21.1-35.5)$ & $8.8(7.1-10.4)$ & $27.9(20.6-35.2)$ & $8.6(7.0-10.2)$ & $29.1(21.5-36.6)$ \\
\hline $\mathrm{DBP}>\mathrm{P} 90, \mathrm{n}=226$ & $8.3(6.8-9.8)$ & $14.9(10.1-19.7)$ & $8.2(6.7-9.8)$ & $15.8^{* *}(10.9-20.6)$ & $8.2(6.7-9.7)$ & $15.9 * *(10.9-20.8)$ \\
\hline $\mathrm{HbA} 1 \mathrm{c}>\mathrm{P} 90, \mathrm{n}=266$ & $10.1(8.0-12.3)$ & $16.0^{\text {n.s. }}(9.8-22.1)$ & $10.1(7.9-12.3)$ & $16.4^{\text {n.s. }}(9.8-22.9)$ & $10.2(8.0-12.4)$ & $15.3^{\text {n.s. }}(9.0-21.6)$ \\
\hline hs-CRP > $2.1 \mathrm{mg} / \mathrm{l}, \mathrm{n}=185$ & $5.7(4.6-6.9)$ & $23.6(17.6-29.7)$ & $5.8(4.6-7.1)$ & $23.2(17.1-29.3)$ & $6.0(4.8-7.1)$ & $21.8(15.9-27.6)$ \\
\hline
\end{tabular}

P90 = Age- and sex-specific 90th percentile; $\mathrm{P} 10$ = age- and sex-specific 10 th percentile; $\mathrm{CI}=$ confidence interval; WC $=$ waist circumference; $\mathrm{WHtR}=$ waist-to-height ratio; $\mathrm{SBP}=$ systolic blood pressure; $\mathrm{DBP}=$ diastolic blood pressure; hs-CRP = high-sensitivity $\mathrm{C}$-reactive protein; $\mathrm{TC}=$ total cholesterol; LDL-C = low-density lipoprotein cholesterol; HDL-C $=$ high-density lipoprotein cholesterol.

${ }^{a}$ Dichotomized at the age- and sex-specific 90th percentile. Differences between $\leq$ P90 and $>$ P90 were highly significant ( $\left.\mathrm{p}<0.001\right)$ unless explicitly mentioned (n.s. $=$ not significant, $* *=p<0.01, *=p<0.05)$, chi-square test.

( $\mathrm{p}<0.001)$. Mean WHR was lower among 14- to 17-year-olds as compared to younger children $(\mathrm{p}<0.001)$. 14- to 17 -yearold boys were taller and heavier than girls in this age group $(\mathrm{p}<0.001)$, but the mean BMI did not statistically differ between the sexes. Among the entire group, the mean SFT was consistently higher for girls than for boys $(p<0.001)$, whereas the mean WC, WHR, and WHtR were higher among boys $(\mathrm{p}<0.001)$. Among boys, the mean serum TC and lipoprotein concentrations were lower in 14- to 17 -year-olds than in 11- to 13 -year-olds $(\mathrm{p}<0.001)$. In contrast, blood lipids did not differ between age groups among girls. The mean SBP and DBP values increased with age in both sexes $(p<0.001)$. At the age 

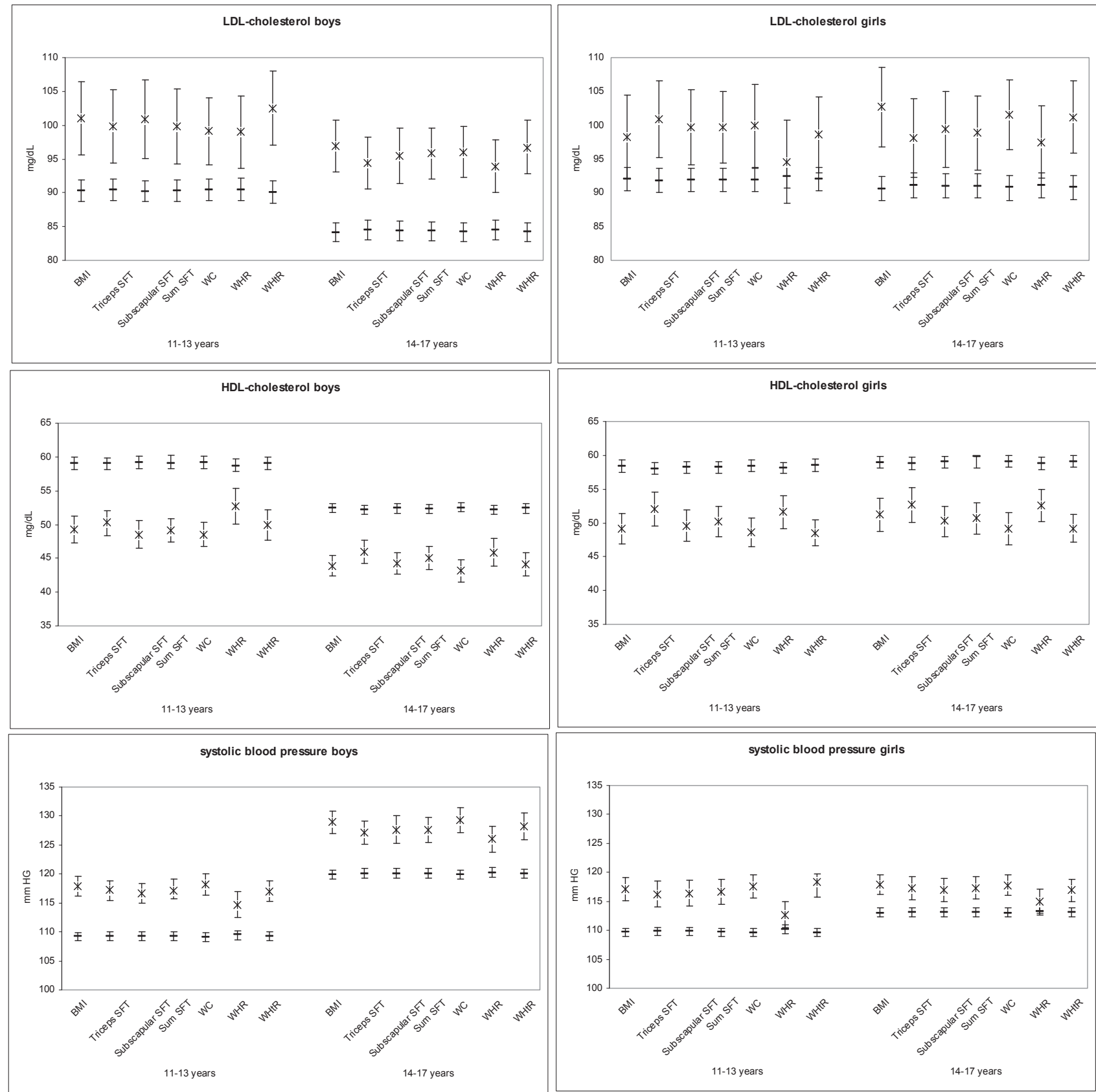

systolic blood pressure girls
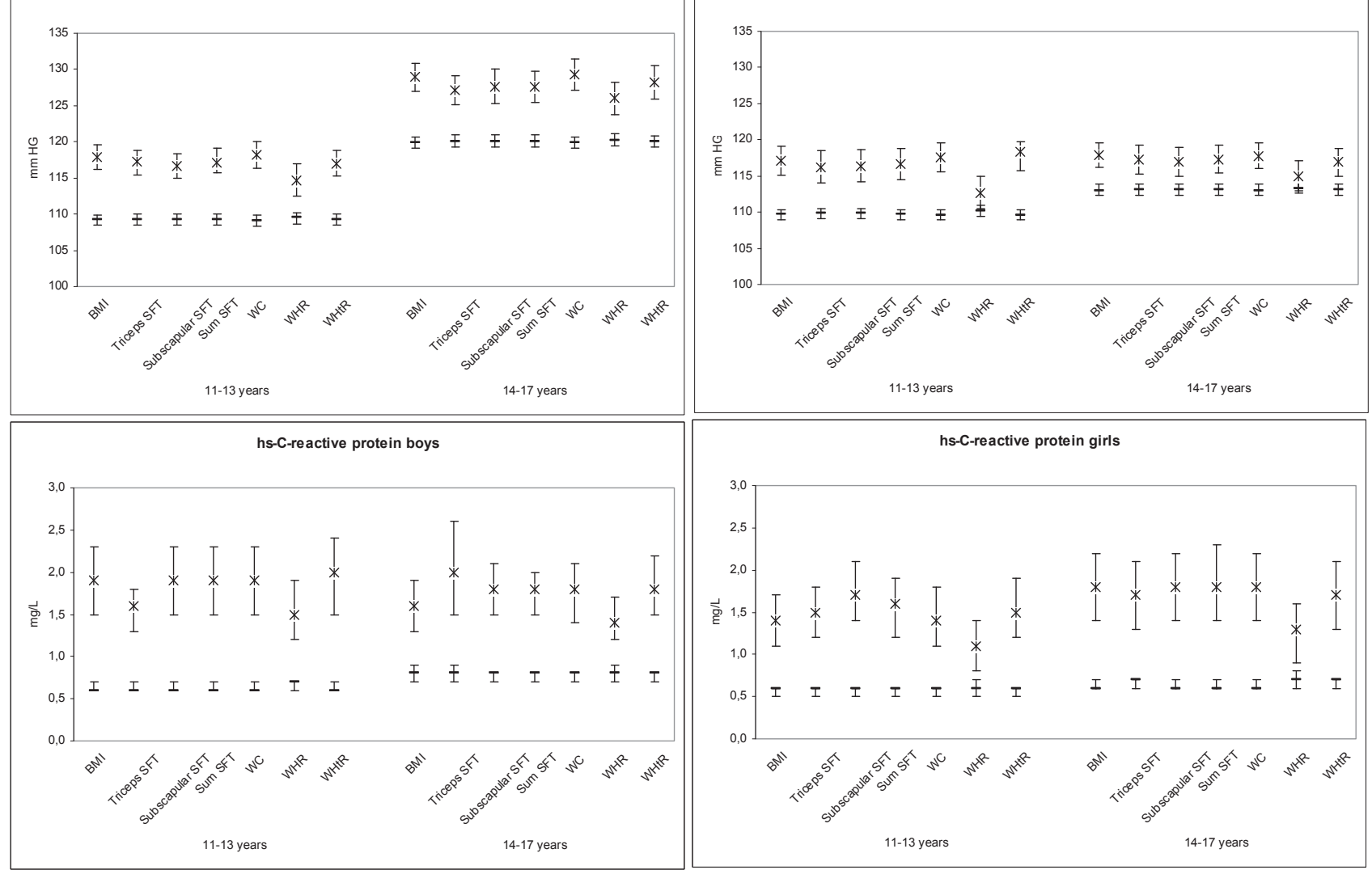

Fig. 1. Means ( $95 \% \mathrm{CI})$ for CVD risk factors according to age group, gender and overweight dichotomized at the age- and sex-specific 90 th percentile. $x=$ overweight $(>90$ th percentile $) ;-=$ normal weight $(\leq 90$ th percentile $) ; \mathrm{CI}=$ confidence interval; SFT $=$ skinfold thickness; WC $=$ waist circumference; WHR = waist-to-hip ratio; WHtR = waist-to-height ratio. 
Table 3. Linear regression of individual CVD risk factors on different indicators of overweight ${ }^{\mathrm{a}}$

\begin{tabular}{|c|c|c|c|c|c|c|c|}
\hline & $\begin{array}{l}\mathrm{TC}, \mathrm{mg} / \mathrm{dl} \\
\mathrm{b}^{\mathrm{b}}(\text { S.E. }) \mathrm{R}^{2}\end{array}$ & $\begin{array}{l}\text { LDL-C, mg/dl } \\
b^{b}\left(\text { S.E.) } R^{2}\right.\end{array}$ & $\begin{array}{l}\text { HDL-C, } \mathrm{mg} / \mathrm{dl} \\
\mathrm{b}^{\mathrm{b}}\left(\text { S.E.) } \mathrm{R}^{2}\right.\end{array}$ & $\begin{array}{l}\text { SBP, } \mathrm{mm} \mathrm{Hg} \\
\mathrm{b}^{\mathrm{b}}(\text { S.E. }) \mathrm{R}^{2}\end{array}$ & $\begin{array}{l}\text { DBP, } \mathrm{mm} \mathrm{Hg} \\
\text { b }^{\mathrm{b}} \text { (S.E.) } \mathrm{R}^{2}\end{array}$ & $\begin{array}{l}\text { HbA1c, \% } \\
b^{b}\left(\text { S.E.) } R^{2}\right.\end{array}$ & $\begin{array}{l}\text { hs-CRP, } \mathrm{mg} / \mathrm{l} \\
\mathrm{b}^{\mathrm{b}}\left(\text { S.E.) } \mathrm{R}^{2}\right.\end{array}$ \\
\hline \multicolumn{8}{|l|}{ Boys } \\
\hline BMI & $13.4(2.2) 0.09$ & 11.9 (1.7) 0.05 & $-9.2(0.7) 0.13$ & $9.1(0.7) 0.32$ & $3.6(0.6) 0.12$ & $-0.03^{\text {n.s. }}(0.03)<0.01$ & $1.0(0.1) 0.06$ \\
\hline Triceps SFT & 10.3 (1.9) 0.08 & $9.2(1.6) 0.05$ & $-7.5(0.8) 0.12$ & $7.6(0.7) 0.30$ & $2.8(0.6) 0.11$ & $0.01^{\text {n.s. }}(0.03)<0.01$ & $0.9(0.1) 0.05$ \\
\hline Subscapular SFT & 11.5 (2.1) 0.09 & 10.8 (1.7) 0.05 & $-9.3(0.8) 0.13$ & $7.8(0.8) 0.30$ & $3.2(0.6) 0.11$ & $0.03^{\text {n.s. }}(0.03)<0.01$ & $1.1(0.1) 0.07$ \\
\hline Sum of SFT & $11.8(2.0) 0.09$ & 10.3 (1.6) 0.05 & $-8.7(0.8) 0.13$ & $7.8(0.7) 0.30$ & $2.8(0.6) 0.11$ & $0.02^{\text {n.s. }}(0.03)<0.01$ & $1.1(0.1) 0.06$ \\
\hline WC & 11.1 (1.9) 0.09 & 10.3 (1.6) 0.05 & $-10.2(0.7) 0.14$ & $9.3(0.7) 0.32$ & $4.1(0.6) 0.12$ & $-0.04^{\text {n.s. }}(0.03)<0.01$ & $1.1(0.1) 0.07$ \\
\hline WHR & 9.5 (1.7) 0.08 & 8.5 (1.6) 0.04 & $-6.3(0.9) 0.11$ & $5.9(0.8) 0.29$ & $2.7(0.7) 0.11$ & $-0.01^{\text {n.s. }}(0.03)<0.01$ & $0.7(0.1) 0.03$ \\
\hline WHtR & 13.8 (2.1) 0.09 & 11.9 (1.7) 0.05 & $-9.0(0.8) 0.13$ & $8.3(0.8) 0.31$ & $3.7(0.6) 0.12$ & $-0.02^{\text {n.s. }}(0.04)<0.01$ & $1.2(0.1) 0.08$ \\
\hline \multicolumn{8}{|l|}{ Girls } \\
\hline BMI & $8.5(2$ & $9.2(2.2) 0.02$ & $-8.3(0$ & $5.9(0.7) 0.09$ & $2.7(0.5) 0.06$ & $0.07 *(0$ & $1.1(0.1) 0.09$ \\
\hline Triceps SFT & $8.5(2.2) 0.02$ & $7.8(2.1) 0.01$ & $-6.1(1.0) 0.03$ & $5.3(0.7) 0.08$ & $1.8(0.5) 0.06$ & $0.05^{\text {n.s. }}(0.03) 0.01$ & $1.0(0.1) 0.08$ \\
\hline Subscapular SFT & $7.3 * *(2.2) 0.02$ & $8.1(2.0) 0.02$ & $-8.5(0.9) 0.05$ & $5.2(0.8) 0.08$ & $2.1(0.6) 0.06$ & $0.07 *(0.03) 0.01$ & $1.2(0.1) 0.11$ \\
\hline Sum of SFT & $6.8 * *(2.1) 0.02$ & 7.7 (1.9) 0.01 & $-8.0(0.9) 0.04$ & $5.5(0.7) 0.09$ & $1.9(0.5) 0.06$ & $0.06^{\text {n.s. }}(0.03) 0.01$ & $1.1(0.1) 0.10$ \\
\hline WC & $8.2(2.2) 0.02$ & $9.6(2.1) 0.02$ & $-9.6(0.9) 0.06$ & $6.2(0.7) 0.09$ & $2.9(0.5) 0.07$ & $0.09 * *(0.03) 0.01$ & $1.1(0.1) 0.09$ \\
\hline WHR & $6.0^{* *}(2.2) 0.01$ & $4.3 *(2.0) 0.01$ & $-6.4(0.9) 0.03$ & $2.3 * *(0.8) 0.06$ & $0.9^{\text {n.s. }}(0.5) 0.05$ & $0.03^{\text {n.s. }}(0.04) 0.01$ & $0.5(0.1) 0.03$ \\
\hline WHtR & $7.5(2.0) 0.02$ & $8.3(2.0) 0.02$ & $-9.7(0.9) 0.06$ & $5.9(0.7) 0.09$ & $2.5(0.5) 0.06$ & $0.08 *(0.03) 0.01$ & $1.0(0.1) 0.08$ \\
\hline
\end{tabular}

SFT = Skinfold thickness; $\mathrm{WC}=$ waist circumference; $\mathrm{WHR}=$ waist-to-hip ratio; $\mathrm{WHtR}=$ waist-to-height ratio; $\mathrm{TC}=$ total cholesterol;

LDL-C = low-density lipoprotein cholesterol; HDL-C = high-density lipoprotein cholesterol; SBP = systolic blood pressure; DBP = diastolic blood pressure; hs-CRP = high-sensitivity C-reactive protein; S.E. = standard error; $\mathrm{R}^{2}=$ proportion of variance explained by the model.

${ }^{a}$ Dichotomized at the 90th age- and sex-specific percentile. ${ }^{b}$ Regression coefficients (adjusted for age and pubertal stage) were highly significant $(\mathrm{p}<0.001)$, unless stated otherwise (n.s. $=$ not significant, $* *=p<0.01, *=p<0.05)$. Differences between $\leq P 90$ and $>$ P90 were highly significant $(\mathrm{p}<0.001)$ unless explicitly mentioned (n.s. $=$ not significant, $* *=\mathrm{p}<0.01, *=\mathrm{p}<0.05)$, chi-square test.

of 14- to 17 years, boys had significantly lower serum TC and lipoprotein concentrations and higher SBP and DBP than girls $(\mathrm{p}<0.001)$. Mean hs-CRP concentrations were slightly higher among 14- to 17-year-olds than in the younger age group, irrespective of gender. There were no considerable differences according to age or gender in the mean $\mathrm{HbA} 1 \mathrm{c}$ levels.

As shown in figure 1, irrespective of the indicator chosen, boys and girls with overweight (> P90) had consistently higher mean SBP, LDL-C, and hs-CRP, and lower HDL-C compared to adolescents with normal weight $(\leq \mathrm{P} 90)$ for each indicator of overweight. We also found higher mean levels of DBP and serum TC in relation to overweight status, while no mean differences in HbA1c were observed (data not shown).

For all CVD risk factors except $\mathrm{HbA} 1 \mathrm{c}$, the prevalence of boys and girls exceeding the defined risk factor cut-off was almost 2- to 4-fold higher if they were overweight as defined by BMI, WC or WHtR, except for LDL-C among girls (table 2). Results from linear regression models for the various CVD risk factors and dichotomized measures of overweight (> P90 vs. $\leq$ P90), adjusted for age in years and pubertal stage, are shown in table 3 . All cardiovascular risk factors except $\mathrm{HbA} 1 \mathrm{c}$ were consistently and highly significantly related to the various measures of overweight among both sexes, independent of age and pubertal status. As demonstrated by the regression coefficients, overweight as defined by WC showed the strongest association with SBP and DBP among both sexes. Among boys, WHtR showed the highest association with serum TC and LDL-C as well as with hs-CRP concentrations, and BMI (as well as WHtR) with LDL-C. Among girls, BMI and triceps SFT showed the highest association with serum TC, WC with LDL-C, WHtR with HDL-C, and subscapular SFT with hs-CRP. Age- and puberty-adjusted differences in mean CVD risk factors between those with and without overweight were for example up to $9 \mathrm{~mm} \mathrm{Hg}$ for SBP, $4 \mathrm{~mm} \mathrm{Hg}$ for DBP, $12 \mathrm{mg} / \mathrm{dl}$ for LDL-C, $-10 \mathrm{mg} / \mathrm{dl}$ for HDL-C, and $1 \mathrm{mg} / \mathrm{l}$ for CRP. Excluding obese individuals with measures of BMI and other indices of relative body weight beyond the 95th age- and sex-specific percentile reduced the strength of the observed associations, but the associations remained statistically significant.

Additionally, the percentage of body fat (calculated by using the skinfold equation of Slaughter [21]) was used as an overweight measure. It was shown that the percentage of body fat is not more useful than other overweight measures. In fact, the percentage of body fat led to results similar to those of the sum of SFT (data not shown).

\section{Discussion}

In this nationally representative study of 11- to 17 -year-old boys and girls in Germany, overweight as defined by various anthropometric measures, including BMI, WC, WHR, WHtR, 
and SFT, which were significantly related to adverse levels of SBP and DBP, serum lipoproteins and serum CRP, but not to HbA1c, BMI, WHtR, and WC, consistently showed stronger associations with CVD risk factors than measures of SFT or WHR. Age- and puberty-adjusted differences in mean CVD risk factor levels between children and adolescents with and without overweight were substantial. The prevalence of girls and boys exceeding the 90th percentile cut-offs for CVD risk factors was 2-4-fold higher among those with and without overweight.

The aim of the study was to conduct a systematic and population-based comparison of different anthropometric measures and to evaluate which measure of overweight shows the strongest association with CVD risk. For reasons of sample size considerations and to ensure statistical comparability, definitions of overweight according to the various anthropometric measures were consistently based on the 90th ageand sex-specific percentiles of the net study sample. The focus had to be on adolescents with percentile values within the upper margin of the distribution. For this purpose, using the 90th percentile as threshold is an appropriate approach [6]. Using a higher percentile (for example the 95th percentile) would have markedly reduced the numbers of observations in the upper groups and hence limited the statistical power of comparisons.

In a German study of 4- to 18-year-old overweight children and adolescents referred to obesity centers, the degree of overweight was significantly and positively associated with SBP and DBP. In addition, HDL-C and overweight were weakly and negatively associated, while no association between overweight and TC or LDL-C was observed [7]. The latter observation disagrees with the results of the present study, which may at least partly be explained by methodological differences. A relationship between overweight and serum lipoproteins might be evident only in higher age groups and lipoproteins may be modulated by genetic or developmental factors $[22,23]$. It has also been proposed that $\mathrm{HbA} 1 \mathrm{c}$ is a good predictor of later development of type 2 diabetes mellitus in children [24] and has been positively related to BMI [10]. In our study, there was only a weak association between overweight and HbA1c among girls and none among boys. Overall, there was no large variation in HbA1c concentrations. The 90th age- and sex-specific percentile of HbA1c ranged between $5.3 \%$ and $5.4 \%$, which does not imply elevated levels.

Only few studies systematically compared different indicators of childhood obesity with respect to their association with CVD risk factors. In a study of Greek-Cypriot children aged 10-14 years, SBP, DBP, and LDL-C were significantly higher among children exceeding the 75 th percentile for various overweight measures compared to the other children. The differences were most pronounced if WC or WHtR were used to define overweight [8]. In contrast, a study of 9- to 11-year-old children and 13- to 16-year-old adolescents in
Germany found that various obesity measures were similarly associated with blood pressure and blood lipid concentrations [6]. In agreement with our results among girls, the strength of the association with blood pressure was higher for WC than for BMI. In the Bogalusa Heart Study, WHtR showed stronger associations with lipids and lipoproteins, whereas BMI was more closely related to blood pressure and insulin levels [3].

Our results show a weaker association between CVD risk factors and WHR and SFT, as compared to WC, WHtR and BMI, in particular among boys. Among adults, WHR was associated with cardiovascular events and diabetes mellitus $[25,26]$. However, some studies have shown that WHR is not strongly correlated to CVD risk factors among children [27, 28]. Most likely, this is explained by the fact that children still undergo developmental changes of body fat distribution. Furthermore, a weaker association of CVD risk factors with SFT compared to weight-to-height indices has been found [2]. Only one set of SFT at two locations has been measured, which may not be sufficiently reliable as an indicator of body fat [29]. As measurements of SFT are particularly difficult to standardize due to observer bias and biological differences in fat distribution, misclassification may have diffused the association with CVD risk factors.

The results of the present study are based on a large nationally representative sample of 11- to 17-year-olds in Germany. However, there are several limitations. No fasting state blood samples were available, which has to be considered in the interpretation of the results. Risk factors were mainly analyzed as continuous variables, but an additional reflection using clinically relevant cut-offs could help to evaluate the public health relevance. There is, however, no evidence regarding the clinically relevant cut-offs for serum lipids [22, 30, $31]$ or blood pressure $[32,33]$ from long-term prospective studies from childhood into adulthood. Except for hs-CRP, cut-off levels for the CVD risk factors were defined by the age- and sex-specific 90th percentiles (10th percentile for HDL-C) observed in the KiGGS population. A further limitation is that we cannot exclude misclassification according to pubertal stage, as Tanner stages were based on self-assessment of pubic hair status. However, it may still be useful as a proxy for pubertal stage. Furthermore, we excluded persons who used particular medications that would disturb the observed associations between relative weight and CVD risk factors. However, analyses including all participants showed essentially similar results. In conclusion, the present results demonstrate that BMI, WC, and WHtR are easily applicable measures of overweight that appear to be relevant for CVD risk assessment among children and adolescents. We demonstrated a consistent association between major CVD risk factors and overweight as defined by various indicators in a nationally representative survey of 11- to 17-year-old German inhabitants. However, due to the cross-sectional design, a causal interpretation of associations is not possible. For (indi- 
vidual) risk assessment, health professionals should not only examine the weight status but additionally health indicators such as blood pressure and blood lipid profile. Other information like family history of diseases and indicators of chronic inflammation and fat distribution may also be useful for indirect risk assessment. The fact that an association between overweight and several CVD risk factors is already seen among young adolescents should be considered within the framework of prevention and treatment activities.

\section{Acknowledgements}

KiGGS was funded by the German Federal Ministry of Health, the German Federal Ministry of Education and Research, and the Robert Koch Institute.

\section{Disclosure Statement}

None of the authors had any conflict of interest.

\section{References}

$>_{1}$ Botton J, Heude B, Kettaneh A, Borys JM, Lommez A, Bresson JL, Ducimetiere P, Charles MA Cardiovascular risk factor levels and their relationships with overweight and fat distribution in children: the Fleurbaix Laventie Ville Sante II study. Metabolism 2007;56:614-622.

2 Freedman DS, Dietz WH, Srinivasan SR, Berenson GS: The relation of overweight to cardiovascular risk factors among children and adolescents: the Bogalusa Heart Study. Pediatrics 1999;103:1175-1182.

-3 Freedman DS, Kahn HS, Mei Z, Grummer-Strawn LM, Dietz WH, Srinivasan SR, Berenson GS: Relation of body mass index and waist-to-height ratio to cardiovascular disease risk factors in children and adolescents: the Bogalusa Heart Study. Am J Clin Nutr 2007;86:33-40.

4 Freedman DS, Katzmarzyk PT, Dietz WH, Srinivasan SR, Berenson GS: Relation of body mass index and skinfold thicknesses to cardiovascular disease risk factors in children: the Bogalusa Heart Study. Am J Clin Nutr 2009;90:210-216.

$\checkmark 5$ l'Allemand D, Wiegand S, Reinehr T, Muller J, Wabitsch M, Widhalm K, Holl R: Cardiovascular risk in 26,008 European overweight children as established by a multicenter database. Obesity (Silver Spring) 2008;16:1672-1679.

6 Plachta-Danielzik S, Landsberg B, Johannsen M, Lange D, Muller MJ: Association of different obesity indices with blood pressure and blood lipids in children and adolescents. Br J Nutr 2008;100:208-218.

7 Reinehr T, Andler W, Denzer C, Siegried W, Mayer H, Wabitsch M: Cardiovascular risk factors in overweight German children and adolescents: relation to gender, age and degree of overweight. Nutr Metab Cardiovasc Dis 2005;15:181-187.

$\checkmark 8$ Savva SC, Tornaritis M, Savva ME, Kourides Y, Panagi A, Silikiotou N, Georgiou C, Kafatos A Waist circumference and waist-to-height ratio are better predictors of cardiovascular disease risk factors in children than body mass index. Int $\mathrm{J}$ Obes Relat Metab Disord 2000;24:1453-1458.

9 Weiss R, Dziura J, Burgert TS, Tamborlane WV, Taksali SE, Yeckel CW, Allen K, Lopes M, Savoye M, Morrison J, Sherwin RS, Caprio S: Obesity and the metabolic syndrome in children and adolescents. N Engl J Med 2004;350:2362-2374.

10 Eldeirawi K, Lipton RB: Predictors of hemoglobin A1c in a national sample of nondiabetic children: the Third National Health and Nutrition Examination Survey, 1988-1994. Am J Epidemiol 2003;157: 624-632.

-11 de Ferranti SD, Gauvreau K, Ludwig DS, Newburger JW, Rifai N: Inflammation and changes in metabolic syndrome abnormalities in US adolescents: findings from the 1988-1994 and 1999-2000 National Health and Nutrition Examination Surveys. Clin Chem 2006;52:1325-1330.
12 Ford ES, Galuska DA, Gillespie C, Will JC, Giles WH, Dietz WH: C-reactive protein and body mass index in children: findings from the Third National Health and Nutrition Examination Survey, 19881994. J Pediatr 2001;138:486-492.

13 Visser M, Bouter LM, McQuillan GM, Wener MH, Harris TB: Low-grade systemic inflammation in overweight children. Pediatrics 2001;107:E13.

14 Raitakari OT, Juonala M, Viikari JS: Obesity in childhood and vascular changes in adulthood: insights into the Cardiovascular Risk in Young Finns Study. Int J Obes (Lond) 2005;29(suppl 2):S101S104.

15 Siervogel RM, Wisemandle W, Maynard LM, Guo SS, Chumlea WC, Towne B: Lifetime overweight status in relation to serial changes in body composition and risk factors for cardiovascular disease: the Fels Longitudinal Study. Obes Res 2000;8:422-430.

16 Bjorge T, Engeland A, Tverdal A, Smith GD: Body mass index in adolescence in relation to causespecific mortality: a follow-up of 230,000 Norwegian adolescents. Am J Epidemiol 2008;168:30-37.

17 Pischon T, Boeing H, Hoffmann K, Bergmann M, Schulze MB, Overvad K, van der Schouw YT, Spencer E, Moons KG, Tjonneland A, Halkjaer J, Jensen MK, Stegger J, Clavel-Chapelon F, BoutronRuault MC, Chajes V, Linseisen J, Kaaks R, Trichopoulou A, Trichopoulos D, Bamia C, Sieri S, Palli D, Tumino R, Vineis P, Panico S, Peeters PH, May AM, Bueno-de-Mesquita HB, van Duijnhoven FJ, Hallmans G, Weinehall L, Manjer J, Hedblad B, Lund E, Agudo A, Arriola L, Barricarte A, Navarro C, Martinez C, Quiros JR, Key T, Bingham S, Khaw KT, Boffetta P, Jenab M, Ferrari P, Riboli E: General and abdominal adiposity and risk of death in Europe. N Engl J Med 2008;359:2105-2120.

18 Lloyd LJ, Langley-Evans SC, McMullen S: Childhood obesity and adult cardiovascular disease risk: a systematic review. Int J Obes (Lond) 2010;34:18-28.

19 Kurth BM, Kamtsiuris P, Holling H, Schlaud M, Dolle R, Ellert U, Kahl H, Knopf H, Lange M, Mensink GB, Neuhauser H, Rosario AS, ScheidtNave C, Schenk L, Schlack R, Stolzenberg H, Thamm M, Thierfelder W, Wolf U: The challenge of comprehensively mapping children's health in a nation-wide health survey: design of the German KiGGS-Study. BMC Public Health 2008:8:196.

20 Tanner JM: Growth at Adolescence, ed 2. Oxford, Blackwell Scientific Publications, 1962.

21 Slaughter MH, Lohman TG, Boileau RA, Horswill CA, Stillman RJ, Van Loan MD, Bemben DA: Skinfold equations for estimation of body fatness in children and youth. Hum Biol 1988;60:709-723.

22 Daniels SR, Greer FR: Lipid screening and cardiovascular health in childhood. Pediatrics 2008;122: 198-208.
23 De Simone M, Verrotti A, Cappa M, Iughetti L, Di Cesare E, Palumbo M, Bernabei R, Rosato T: Lipoprotein (a) in childhood: correlations with family history of cardiovascular disease. J Endocrinol Invest 2003;26:414-419.

24 Fagot-Campagna A, Saaddine JB, Flegal KM, Beckles GL: Diabetes, impaired fasting glucose, and elevated HbA1c in U.S. adolescents: the Third National Health and Nutrition Examination Survey. Diabetes Care 2001;24:834-837.

25 Dalton M, Cameron AJ, Zimmet PZ, Shaw JE, Jolley D, Dunstan DW, Welborn TA: Waist circumference, waist-hip ratio and body mass index and their correlation with cardiovascular disease risk factors in Australian adults. J Intern Med 2003; 254:555-563.

26 MacDonald S, Joffres MR, Stachenko S, Horlick L, Fodor G: Multiple cardiovascular disease risk factors in Canadian adults. Canadian Heart Health Surveys Research Group. CMAJ 1992;146:2021-2029.

27 Kelishadi R, Ardalan G, Gheiratmand R, Adeli K, Delavari A, Majdzadeh R; Caspian Study Group: Paediatric metabolic syndrome and associated anthropometric indices: the CASPIAN Study. Acta Paediatr 2006;95:1625-1634.

28 Mirzaei M, Taylor R, Morrell S, Leeder SR: Predictors of blood pressure in a cohort of school-aged children. Eur J Cardiovasc Prev Rehabil 2007;14: 624-629.

29 Reilly JJ, Wilson J, Durnin JV: Determination of body composition from skinfold thickness: a validation study. Arch Dis Child 1995;73:305-310.

30 Labarthe DR, Dai S, Fulton JE: Cholesterol screening in children: insights from Project HeartBeat! and NHANES III. Prog Pediatr Cardiol 2003;17: 169-178.

31 Magnussen CG, Raitakari OT, Thomson R, Juonala M, Patel DA, Viikari JS, Marniemi J, Srinivasan SR, Berenson GS, Dwyer T, Venn A: Utility of currently recommended pediatric dyslipidemia classifications in predicting dyslipidemia in adulthood: evidence from the Childhood Determinants of Adult Health (CDAH) study, Cardiovascular Risk in Young Finns Study, and Bogalusa Heart Study. Circulation 2008;117:32-42.

32 National High Blood Pressure Education Program Working Group on High Blood Pressure in Children and Adolescents: The fourth report on the diagnosis, evaluation, and treatment of high blood pressure in children and adolescents. Pediatrics 2004;114:555-576.

33 Neuhauser HK, Rosario AS, Thamm M, Ellert $\mathrm{U}$ : Prevalence of children with blood pressure measurements exceeding adult cutoffs for optimal blood pressure in Germany. Eur J Cardiovasc Prev Rehabil 2009;16:195-200. 